\title{
Covid-19 worldwide: we need precise data by age group and sex urgently
}

\author{
Raj Bhopal emeritus professor of public health
}

Usher Institute, University of Edinburgh, Edinburgh EH8 9AG, UK

Accurate and interpretable data are essential in guiding our approach to the covid-19 pandemic. Basic epidemiological principles are currently being flouted. ${ }^{1}$ Mostly, as in your article, ${ }^{2}$ case numbers are being reported. This number needs to be converted to a proportion, using the population size as the denominator. Otherwise, how can we tell which countries are being affected the most?

When the rate of disease is highly variable by age, as in covid-19, we need to examine age specific mortality and morbidity and case fatality rates. Given the sex differences, these rates also need to be stratified by sex. Age adjustment, by either the direct or indirect method or statistical models, is too crude when the rates are highly variable across age groups, ${ }^{1}$ although it is better than the overall or crude rates that we are currently seeing, invariably in the media but also in professional journals.

We are being misled about the potential dangers (or not) by using overall or crude death rates. The Chinese overall mortality proportions, for example, will not apply to countries with older age structures, such as Italy or the UK, where mortality will be higher. The Italian proportions will not apply to much of Africa, where the average age of the population is low. Data should be published in 10 year age groups or, even better, 5 year age groups. The data are likely to be reassuring for parents and young people and the opposite for older people. The results are likely to be much more informative than the widely disseminated and extremely crude estimate of $1-2 \%$ mortality or even lower, which is mostly based on China's experience. We can and must do better.

\section{Competing interests: None declared.}

Bhopal RS. Concepts of epidemiology: integrating the ideas, theories, principles and methods of epidemiology. 3rd ed. Oxford University Press, 2016.

2 Tanne JH, Hayasaki E, Zastrow M, Pulla P, Smith P, Rada AG. Covid-19: how doctors and healthcare systems are tackling coronavirus worldwide. BMJ 2020;368:m1090. 10.1136/bmj.m1090 32188598

Published by the BMJ Publishing Group Limited. For permission to use (where not already granted under a licence) please go to http://group.bmj.com/group/rights-licensing/ permissions 